\title{
Influence of the alkyl substitution position on photovoltaic properties of 2D-BDT-based conjugated polymers
}

\author{
Huifeng Yao, Long Ye, Benhu Fan, Lijun Huo* and Jianhui Hou*
}

\begin{abstract}
Three conjugated polymers based on thienyl-substituted benzodithiophene (BDT) and 4,7-bis-thienyl-benzothiadiazole (DTBT) with varied substitution positions of the alkyl side chains were synthesized to investigate the correlations between the structure and photovoltaic performance of the polymer photovoltaic materials. The three polymers named PBDTDTBT- $p$, PBDTDTBT- $o$ and PBDTDTBT- $m$ were characterized by a set of methods including absorption spectroscopy, cyclic voltammetry, thermogravimetric analysis, $\mathrm{X}$-ray diffraction, density functional theory and photovoltaic measurements. The results show that the steric hindrance caused by the different substitution positions of the alky chains has a significant influence on the photovoltaic properties of the polymers. The open-circuit voltage $\left(V_{\text {oc }}\right)$ of the photovoltaic devices based on the three polymers could range from 0.67 to $0.90 \mathrm{~V}$. Clearly, this finding provides us a feasible strategy to optimize the photovoltaic properties by simply changing the positions of the alkyl chains.
\end{abstract}

\section{INTRODUCTION}

Design, synthesis and applications of novel conjugated polymers for polymer solar cells (PSCs) have received substantial attention over the past decades [1-14]. Significant improvements have been achieved in understanding the correlations between polymer structure and photovoltaic performance, which have helped to boost the power conversion efficiency (PCE) over 7\% in several well-known backbones, such as benzodithiophene (BDT) and thienothiophene (TT) (PBDT-TT) [15-28], BDT and benzothiadiazole (BT) (PBDT-BT) [29,30], BDT and thienopyrroledione (TPD) (PBDT-TPD) [31], etc.

Besides the extensive studies on design of new backbone structures, side chain engineering is emerging as an important strategy to optimize the structure of photovoltaic polymers [32-34]. Generally, researchers focus on the length (namely, carbon atom number) and type (straight or branched) of alkyl chains, which all affect the performance of the photovoltaic polymers. Based on the previous studies, several requirements should be considered for high performance polymers. First, alkyl side chain should afford the solubility of the rigid conjugated polymers toward good film-forming property. Second, alky side chain could also tune the optical absorption, molecular energy levels and morphologies of the photovoltaic materials. For instance, a dramatic improvement was obtained in PBDT-TPD based PSCs through a simple tuning of the side chain length, and a high PCE up to $8.5 \%$ was achieved by Cabanetos and coworkers [31]. However, compared with aforementioned cases, only a very few of studies took considerations of the substitution position effect of alky chains in studies of photovoltaic polymers [35-37]. Therefore, to investigate the effect of substitution positions of the alkyl chains should be of great importance for structure optimization of photovoltaic polymers, and this will provide guidance for designing high performance photovoltaic materials.

Previously, we developed an efficient copolymer based on thienyl-substituted BDT and 4,7-di(thiophen-2-yl) benzothiadiazole (DTBT) units, which exhibited a high open-circuit voltage $\left(V_{o c}\right)$ of $\sim 0.9 \mathrm{~V}$ and a PCE over $5 \%$ [38]. In the present work, in order to get more insights into the impact of alky chain substitution positions on photovoltaic properties of the PBDTDTBT polymers [38,39], a long branched para-hexyldecyl, two ortho-dioctyl and two meta-dioctyl side chains were introduced onto the thiophene group in varied positions, respectively. Then three copolymers named PBDTDTBT- $o$, PBDTDTBT- $m$ and PBDTDTBT- $p$ were synthesized (see Scheme 1), and the systematical study revealed the effects of the alkyl chain positions on absorption spectra, molecular energy levels, crystallinities, morphological and photovoltaic properties of the PBDTDTBT polymers.

\section{RESULTS AND DISCUSSION}

Synthesis of the polymers

The synthetic routes of the three copolymers are described

State Key Laboratory of Polymer Physics and Chemistry, Beijing National Laboratory for Molecular Sciences, Institute of Chemistry, Chinese Academy of Sciences, Beijing, 100190, P. R. China

*Corresponding authors (emails: hjhzlz@iccas.ac.cn (Hou J); huolijun@iccas.ac.cn (Huo L)) 


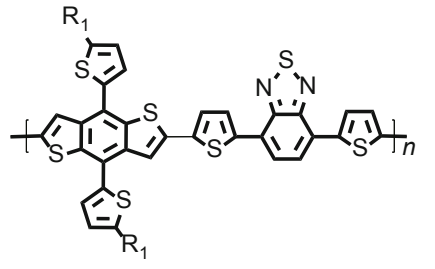

PBDTDTBT- $p$

$\mathrm{R}_{1}=$ 2-hexyldecy

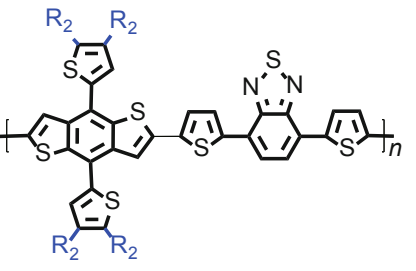

PBDTDTBT-O

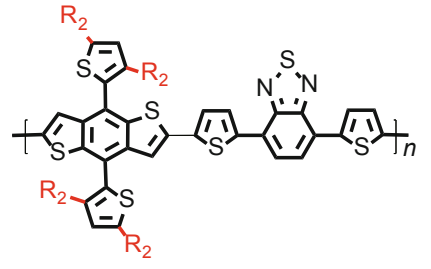

PBDTDTBT- $m$

Scheme 1 Molecular structures of PBDTDTBT based polymers with varied alkyl side chain positions.

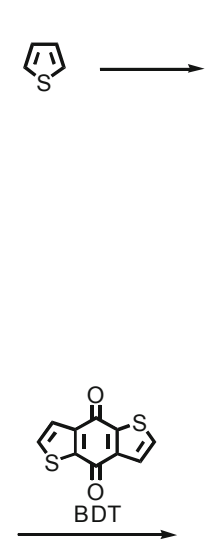

$\mathrm{R}_{1}=$ 2-hexyldecyl $\mathrm{R}_{2}=n$-octyl

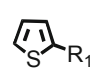
1

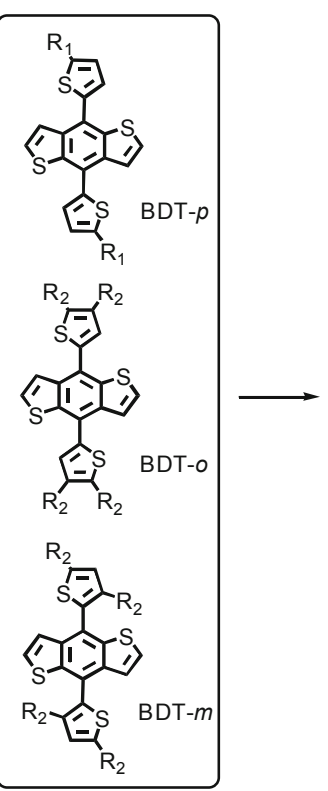<smiles>[R]c1ccsc1Br</smiles>

2

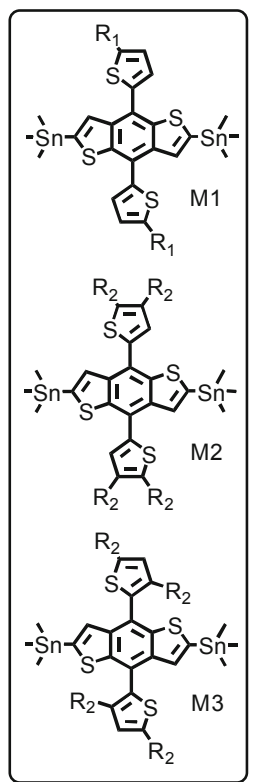<smiles>[R]c1ccc(Br)s1</smiles><smiles></smiles>
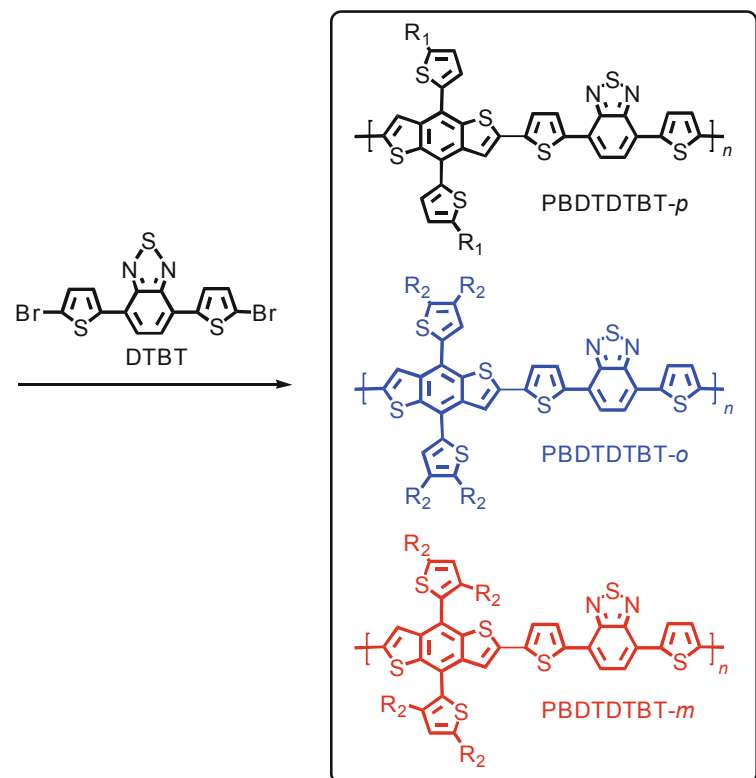

Scheme 2 Synthetic routes of the three kinds of polymers.

in Scheme 2. The thiophene derivatives with different alkyl chains were synthesized and introduced onto BDT units by the same method as reported in our previous work [38], after which the monomers were obtained from the reaction with trimethyltin chloride. The three polymers were prepared through Stille coupling reaction. More synthetic details are given in the Experiment Section. The number average molecular weights $\left(M_{\mathrm{n}}\right)$ of PBDTDTBT- $p$, PBDTDTBT- $o$, PBDTDTBT- $m$ are $28 \mathrm{kDa}$ (polydispersities $(\mathrm{PDI})=1.9), 25 \mathrm{kDa}(\mathrm{PDI}=1.7)$ and $18 \mathrm{kDa}(\mathrm{PDI}=1.8)$, respectively. The thermal stability of the three polymers were studied by thermogravimetric analysis (TGA), and the TGA plots of these polymers are shown in Fig. 1. It can be seen that the decomposition temperatures $\left(T_{\mathrm{d}}\right)$ at $5 \%$

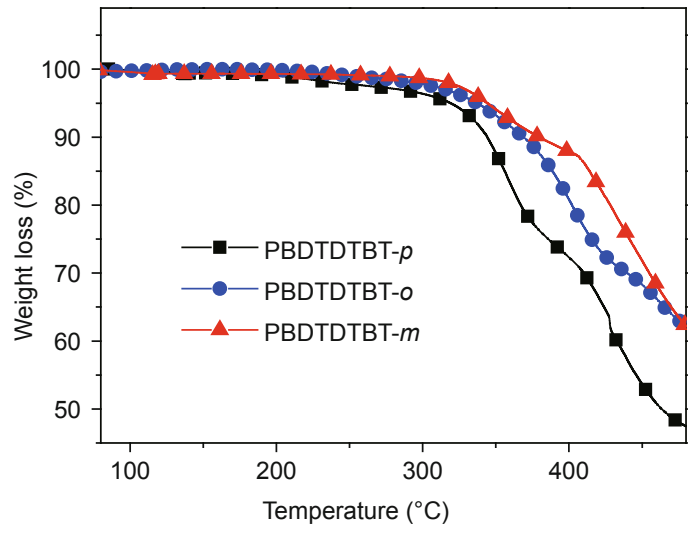

Figure 1 TGA plots of the polymers under the protection of nitrogen with a heating rate of $10^{\circ} \mathrm{C} \mathrm{min}^{-1}$. 
weight loss are all above $300^{\circ} \mathrm{C}$ for the three polymers.

\section{Optical properties}

The UV-vis absorption spectra of the three polymers in chloroform and solid thin films are shown in Fig. 2, and the detailed parameters are listed in Table 1. From Fig. 2a, it can be observed that three absorption bands of these polymers and the corresponding absorption peaks of the three polymers locate at 613, 593 and $579 \mathrm{~nm}$ for PBDTDTBT- $p$, PBDTDTBT- $o$ and PBDTDTBT- $m$ respectively. The optical band gaps calculated according to the absorption edges of the polymer films are listed in Table 1. Interestingly, comparing the absorption spectra of the polymers in solution with that in films from the Fig. $2 b$, the onset points of the absorption of PBDTDTBT- $p$ and PBDTDTBT- $o$ are almost overlapped in solution while $14 \mathrm{~nm}$ red-shift is observed from PBDTDTBT- $o$ to PBDTDTBT- $p$ in thin films. This phenomenon suggests stronger intermolecular $\pi-\pi$
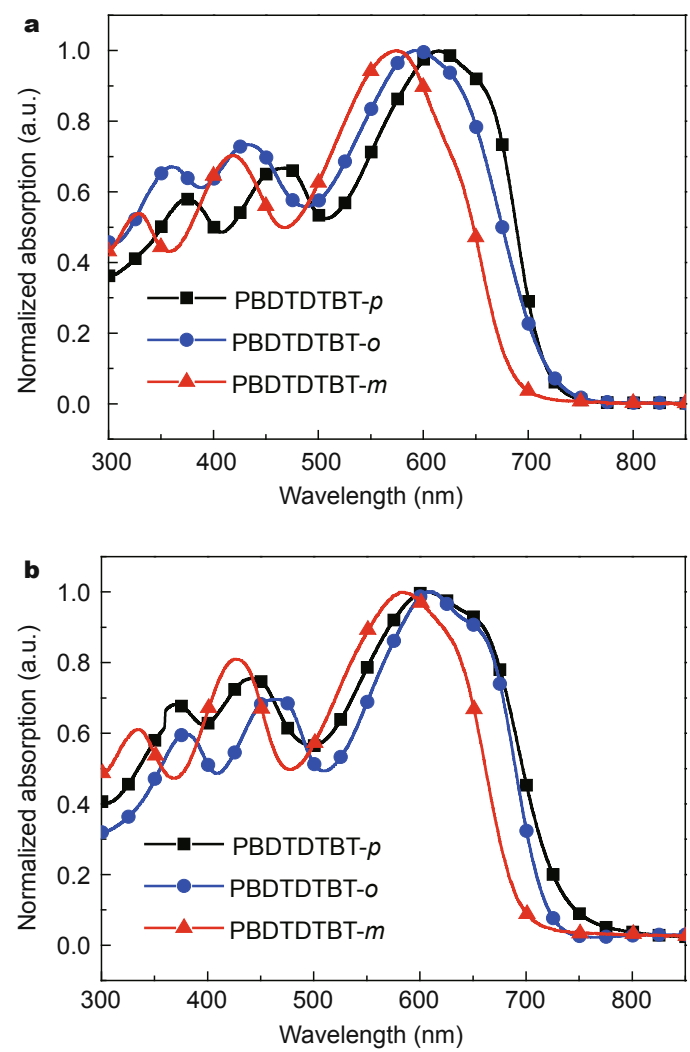

Figure 2 Normalized UV-vis absorption spectra of the three polymers: (a) in chloroform solution, and (b) thin films on quartz.

Table 1 Optical and electrochemical properties of the polymers

\begin{tabular}{cccccc}
\hline \multicolumn{1}{c}{ Polymer } & $\begin{array}{c}\lambda_{\max }(\mathrm{nm}) \\
\text { Solution Film }\end{array}$ & $E_{\mathrm{g}}{ }^{\text {opt }}(\mathrm{eV})$ & $\mathrm{HOMO}(\mathrm{eV})$ & $\mu_{\text {hole }}\left(\mathrm{cm}^{2} \mathrm{~V}^{-1} \mathrm{~s}^{-1}\right)$ \\
\hline PBDTDTBT- $p$ & 613 & 607 & 1.64 & -5.09 & $3.50 \times 10^{-3}$ \\
PBDTDTBT- $o$ & 593 & 613 & 1.68 & -5.11 & $8.61 \times 10^{-3}$ \\
PBDTDTBT- $m$ & 579 & 596 & 1.75 & -5.31 & $9.26 \times 10^{-4}$ \\
\hline
\end{tabular}

interaction may be formed in the PBDTDTBT- $p$ film than in PBDTDTBT- $o$ film, which indicates that two ortho-position substituted alky side chains possess stronger steric hindrance than one para-position substituted alkyls.

\section{Electrochemical properties}

Electrochemical cyclic voltammetry $(\mathrm{CV})$ was used to measure the molecular energy levels of the three polymers. As shown in Fig. 3, all the three polymers show reversible $p$-doping processes. The oxidation potential of PBDTDTBT- $p$ is 0.29 V. PBDTDTBT- $o$ shows a little higher oxidation potential $(0.31 \mathrm{~V})$ than PBDTDTBT- $p$ by $0.02 \mathrm{~V}$. It is obvious that the oxidation potential of PBDTDTBT- $m$ is $(0.51 \mathrm{~V})$ ca. $0.2 \mathrm{~V}$ higher than those of the other two polymers. The highest occupied molecular orbital (HOMO) levels of these polymers were calculated according to the equation: $\mathrm{HOMO}=-e\left(\phi_{\mathrm{ox}}+4.80\right)(\mathrm{eV})$, and the detailed data are listed in Table 1.

\section{Computational study}

In order to further explore the effect of alkyl chain positions on the molecular energy levels and molecular conformations of the polymers, theoretical calculation was performed by using density functional theory (DFT) with the B3LYP/6-31G** basis set (Gaussian 09 [40]). With the purpose of reducing the cost of calculation, only the alkyl substituted BDTs were employed and the long alkyl chains were replaced by $-\mathrm{CH}_{2} \mathrm{CH}_{3}$ group. The calculated molecular geometries and the frontier molecular orbitals are collected in Table 2.

The calculated HOMO levels of BDT- $p$, BDT- $o$, BDT- $m$ change from $-5.11,-5.16$ to $-5.26 \mathrm{eV}$, and the trend is quite consistent with the results of corresponding polymers from $\mathrm{CV}$ tests. The electron density distributions of BDT- $p$, BDT- $o$ have little difference, i.e., the $\pi$-electrons can be delocalized onto both the BDT units and the substituted thio-

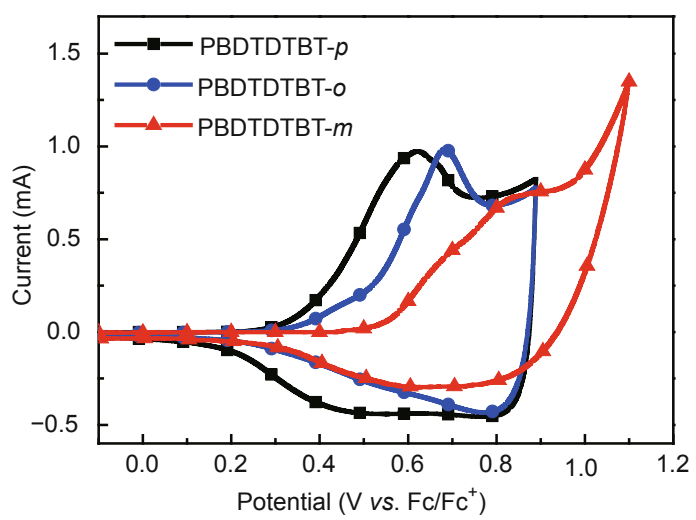

Figure 3 Cyclic voltammogram plots of the polymers on glassy carbon electrode in $0.1 \mathrm{~mol} \mathrm{~L}^{-1} \mathrm{Bu}_{4} \mathrm{NPF}_{6}$ in acetonitrile solution at a scan rate of $50 \mathrm{mV} \mathrm{s}^{-1}$. 
Table 2 Calculated HOMO and lowest unoccupied molecular orbital (LUMO) electron density distributions of the alkyl substituted BDTs

\begin{tabular}{|c|c|c|c|}
\hline BDTs & Conformation & HOMO & LUMO \\
\hline BDT- $p$ & & HOMO $=-5.11 \mathrm{eV}$ & LUMO $=-1.30 \mathrm{eV}$ \\
\hline BDT- $o$ & & LUMO $=-5.16 \mathrm{eV}$ & HOMO $=-1.27 \mathrm{eV}$ \\
\hline BDT- $m$ & & $\begin{array}{c}\text { LUMO }=-5.26 \mathrm{eV} \\
\text { Las }\end{array}$ & HOMO =-1.19 eV \\
\hline
\end{tabular}

phene units. However the $\pi$-electron of BDT- $m$ is mainly localized on the BDT unit. It should be noted that the dihedral angles $(\theta)$ between the thiophene and BDT units change a lot when the alkyls are introduced onto different positions, i.e., the dihedral angles are $52.7^{\circ}, 58.2^{\circ}$ and $87.8^{\circ}$ for BDT- $p$, BDT- $o$ and BDT- $m$, respectively. These results indicate that the steric hindrance is increased gradually from BDT- $p$ to BDT- $o$ and then to BDT- $m$, which is probably the origin of the variations of the absorption spectra and electrochemical results.

\section{$\mathrm{X}$-ray diffraction (XRD) analysis}

$\mathrm{XRD}$ was used to examine the crystalline structure of the polymers in thin film. As shown in Fig. 4, for PBDTDTBT- $p$ and PBDTDTBT- $o$, diffraction signals in (100) direction at $4.26^{\circ}$ (corresponding to a $d$-spacing of $20.72 \AA$ ) and $4.70^{\circ}$ (a $d$-spacing of $18.78 \AA$ ) are observed distinctly. The increased distance of laminar spacing from PBDTDTBT- $o$ to PBDTDTBT- $p$ may be caused by the longer alkyl chain of 2-hexyldecyl than octyl. For PBDTDTBT- $m$ film, no clear diffraction peak can be observed in this region, which means PBDTDTBT- $m$ has less ordered arrangement in this direction. The polymers of PBDTDTBT- $p$, PBDTDTBT- $o$ and PBDTDTBT- $m$ exhibit weak but clear diffraction signals in the direction of $(010)$ at $25.36^{\circ}, 24.57^{\circ}$ and $23.31^{\circ}$, respectively, corresponding to $\pi-\pi$ stacking distances of 3.52, 3.61 and 3.81 $\AA$. The intensity of (100) reflection peaks

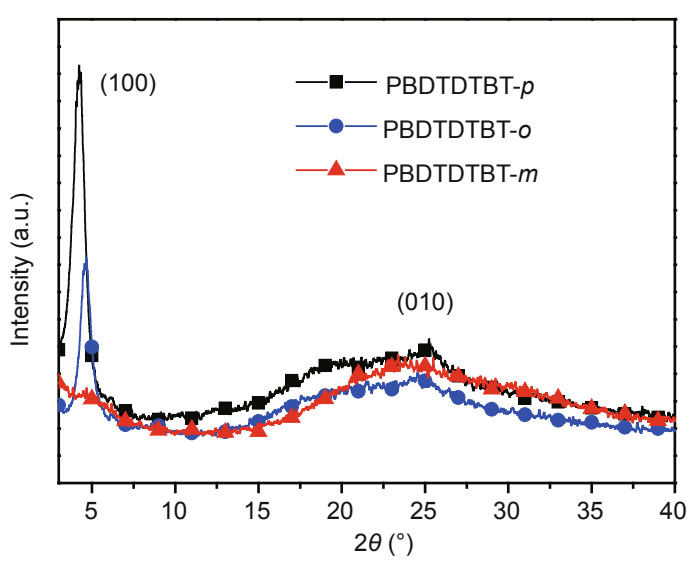

Figure 4 X-ray diffraction patterns of three polymers films casted from chloroform solutions.

decreased a lot from PBDTDTBT- $p$ and PBDTDTBT- $o$ to PBDTDTBT- $m$. The larger $\pi-\pi$ stacking distance and weaker lamellar reflection indicate that PBDTDTBT- $p$ possesses the most orderly arrangement while PBDTDTBT- $m$ has the worst. Moreover, the results are consistent with the phenomenon observed in the absorption spectra and the theoretical calculation.

\section{Hole mobility}

Hole mobilities of the blend films based on the three PBDT- 
DTBT polymers were measured by using space-charge-limited current (SCLC) method and the results are listed in Table 1. In the SCLC measurement, a device configuration of indiumtin oxide (ITO)/poly(3,4-ethylenedioxythiophene): poly(styrenesulfonate)(PEDOT:PSS)/polymer:P$\mathrm{C}_{71} \mathrm{BM} / \mathrm{Au}(80 \mathrm{~nm})$ and the optimal processing conditions in PSC devices were used. The hole mobilities of PBDTDTBT- $p$, PBDTDTBT- $o$ and PBDTDTBT- $m$ were calculated as $3.50 \times 10^{-3}, 8.61 \times 10^{-3}$ and $\left.9.26 \times 10^{-4} \mathrm{~cm}^{2} \mathrm{~V}^{-1} \mathrm{~s}^{-1}\right)$, respectively (Fig. 5).

\section{Photovoltaic behaviors}

PSCs with a device structure of ITO/PEDOT:PSS/ polymer: $\mathrm{PC}_{71} \mathrm{BM} / \mathrm{Ca}(20 \mathrm{~nm}) / \mathrm{Al}(100 \mathrm{~nm})$ were fabricated to investigate the photovoltaic properties of the polymers, and the donor/acceptor (D/A) weight ratios were optimized by using dichlorobenzene (DCB) as the processing solvent. In order to acquire the optimal performances of these devices, thermal annealing was also carried out. $J-V$ characteristics are shown in Fig. 6 and the corresponding results are summarized in Table 3.

The $V_{\text {oc }}$ values of the optimal devices fabricated based on PBDTDTBT- $p$, PBDTDTBT- $o$ and PBDTDTBT- $m$ are quite different, changing from $0.67,0.75$ to $0.90 \mathrm{~V}$, which

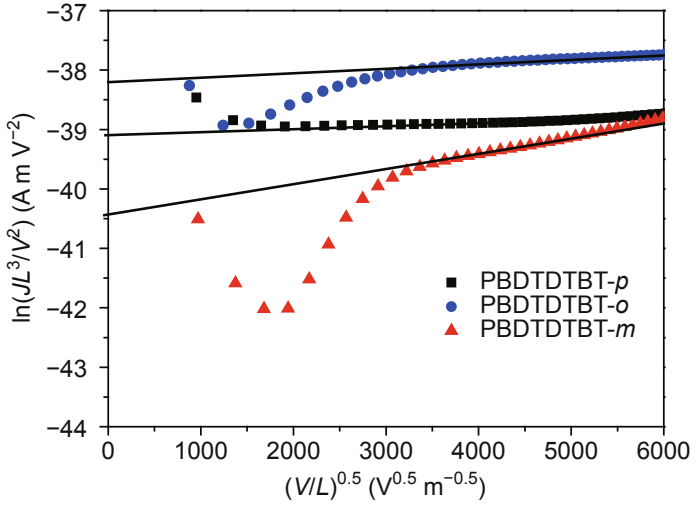

Figure $5 \ln \left(J L^{3} / V^{2}\right) v s$. $(V / L)^{0.5}$ plots of the polymer:PC ${ }_{71} \mathrm{BM}$ blends for the SCLC measurements.

are highly dependent to their different HOMO levels. For PSC devices based on PBDTDTBT- $p$, a best PCE of $3.48 \%$ with a low $V_{\text {oc }}$ of $0.67 \mathrm{~V}$ was obtained under a D/A ratio of $1: 1$ after thermal annealing at $110^{\circ} \mathrm{C}$ for 10 minutes. The processing condition of PBDTDTBT- $o$ was the same with that of PBDTDTBT- $p$. A higher $V_{\text {oc }}$ of $0.75 \mathrm{~V}$ with a better PCE of 5.76\% was achieved in the devices based on PBDTDTBT- $o$. The devices of PBDTDTBT- $m$ shows the highest $V_{\text {oc }}$ of $0.90 \mathrm{~V}$, and the optimal D/A weight ratio was
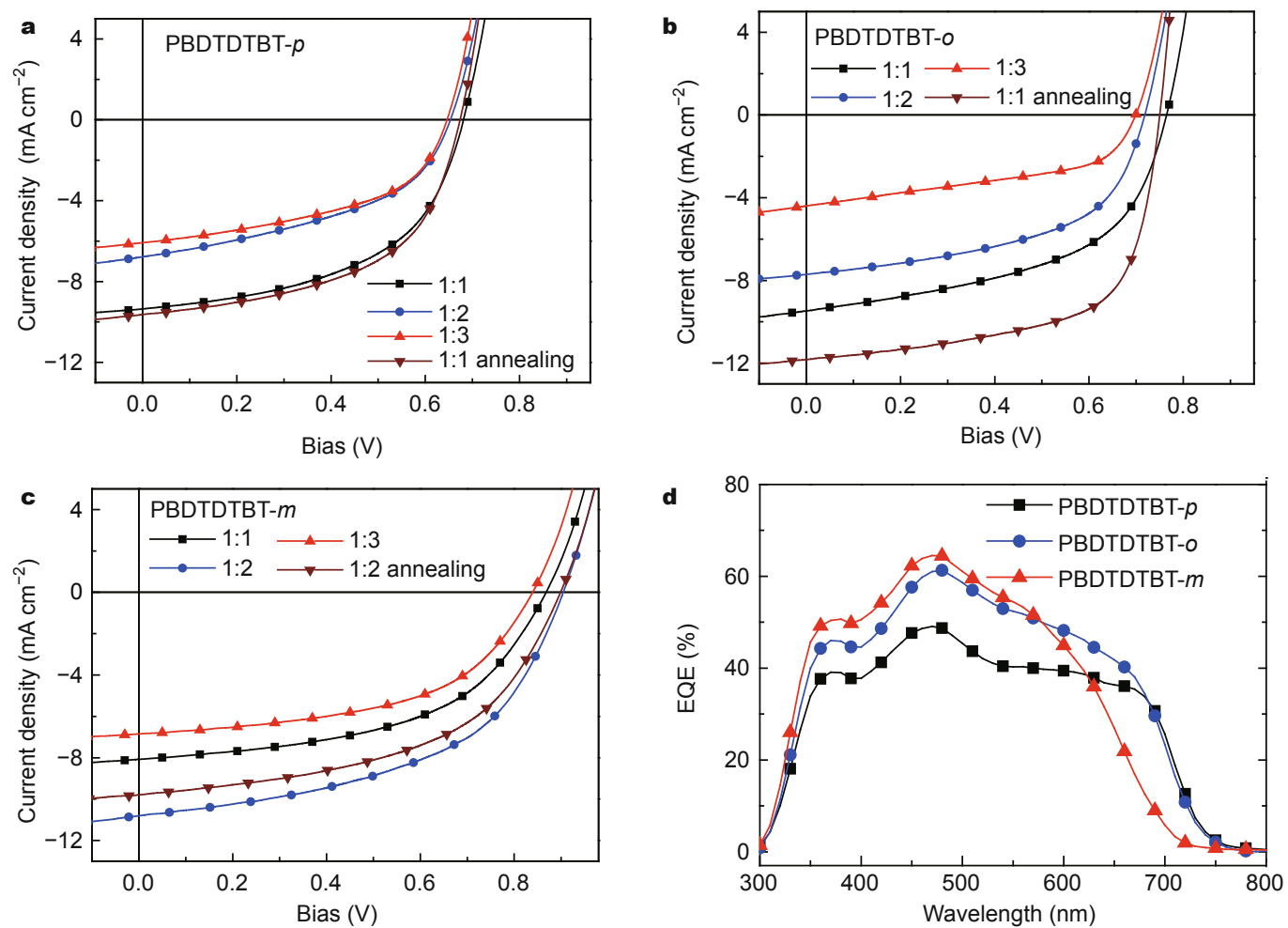

Figure $6 \mathrm{~J}$ - $V$ curves of the devices based on polymers/PC ${ }_{71} \mathrm{BM}$ with different donor/acceptor ratios and annealing condition under illumination of $\mathrm{AM}$ $1.5 \mathrm{G}, 100 \mathrm{~mW} \mathrm{~cm}^{-2}$ : (a) BDTDTBT- $p$, (b) PBDTDTBT- $o$, (c) PBDTDTBT- $m$; (d) the external quantum efficiency (EQE) curves of the PSCs devices fabricated by the optimal conditions. 
Table 3 Photovoltaic parameters of the PSCs based on the PBDTDTBT/PC ${ }_{71} \mathrm{BM}$

\begin{tabular}{|c|c|c|c|c|c|c|}
\hline Polymer & Weight ratio & $V_{\mathrm{oc}}(\mathrm{V})$ & $J_{\mathrm{sc}}\left(\mathrm{mA} \mathrm{cm}^{-2}\right)$ & $F F(\%)$ & PCE (\%) & Thickness (nm) \\
\hline \multirow[t]{4}{*}{ PBDTDTBT- $p$} & $1: 1$ & 0.68 & 9.35 & 51 & 3.25 & - \\
\hline & $1: 2$ & 0.65 & 6.77 & 45 & 2.00 & - \\
\hline & $1: 3$ & 0.65 & 6.08 & 49 & 1.92 & - \\
\hline & $1: 1^{\mathrm{a}}$ & 0.67 & 9.63 & 54 & 3.48 & 95 \\
\hline \multirow[t]{4}{*}{ PBDTDTBT- $o$} & $1: 1$ & 0.76 & 9.47 & 52 & 3.78 & - \\
\hline & $1: 2$ & 0.72 & 7.71 & 53 & 2.94 & - \\
\hline & $1: 3$ & 0.70 & 3.96 & 49 & 1.37 & - \\
\hline & $1: 1^{\mathrm{a}}$ & 0.75 & 11.82 & 65 & 5.76 & 105 \\
\hline \multirow[t]{4}{*}{ PBDTDTBT- $m$} & $1: 1$ & 0.87 & 8.07 & 51 & 3.61 & - \\
\hline & $1: 2$ & 0.90 & 10.81 & 53 & 5.16 & 98 \\
\hline & $1: 3$ & 0.85 & 6.85 & 57 & 3.32 & - \\
\hline & $1: 2^{\mathrm{a}}$ & 0.90 & 9.79 & 55 & 4.85 & - \\
\hline
\end{tabular}

a) thermal annealing at $110^{\circ} \mathrm{C}$ for $10 \mathrm{~min}$

1:2. Compared with the other polymers, the $J_{\text {sc }}$ decreased slightly after thermal annealing in the PBDTDTBT- $m$ case, so a PCE of $5.16 \%$ with the highest $V_{\text {oc }}$ of $0.90 \mathrm{~V}$ was obtained from the condition without post-treatment. The active layer thicknesses of the optimal PSC devices were around 95-105 $\mathrm{nm}$.

\section{Morphology}

The morphologies of the blend films based on the three polymers were studied by atomic force microscopy (AFM). Fig. 7 shows the AFM height images of the three blend films coated by the optimal conditions. The root mean square (RMS) roughness values of PBDTDTBT- $p: \mathrm{PC}_{71} \mathrm{BM}$, PBDTDTBT- $o: \mathrm{PC}_{71} \mathrm{BM}$ are 3.48 and $2.21 \mathrm{~nm}$ respectively, while PBDTDTBT- $m$ has a higher RMS of $5.11 \mathrm{~nm}$. The random arrangement of PBDTDTBT- $m$ may result in a relatively higher RMS when the polymer chains stack to each other. The discrepancy in morphology should be connected to the difference in $J_{\mathrm{sc}}$ values of the devices and consequently affects the overall efficiency.

\section{CONCLUSION}

In summary, to get a comprehensive insight into the impact of alkyl substitution positions on photovoltaic properties
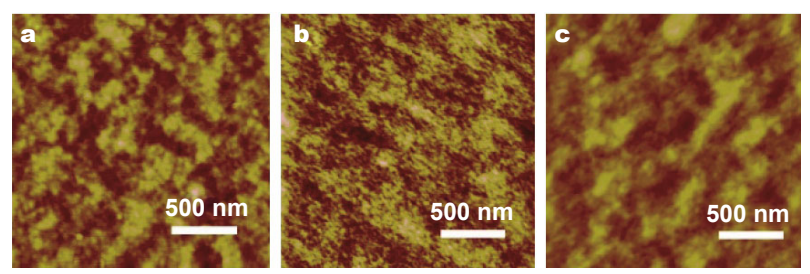

Figure $7 \mathrm{AFM}$ height images $(2 \mu \mathrm{m} \times 2 \mu \mathrm{m})$ of polymer: $\mathrm{PC}_{71} \mathrm{BM}$ blend films fabricated by the optimal conditions: (a) PBDTDTBT- $p$, (b) PBDTDTBT- $o$, (c) PBDTDTBT- $m$. of the 2D-BDT-based polymers, three polymers named PBDTDTBT- $p$, PBDTDTBT- - , PBDTDTBT- $m$ with the identical conjugated backbone were designed and synthesized. Due to the different steric hindrance caused by the substitution positions, these polymers exhibit different optical and electrical properties, and also the molecular packing and surface morphologies of these polymer films are also very different. In detail, PBDTDTBT- $o$ and PBDTDTBT- $p$ show little difference in optical band gaps and energy levels for their relative small discrepancy in steric hindrance, while PBDTDTBT- $m$ exhibits the largest band gap and the deepest HOMO level among these polymers, due to the strongest steric hindrance caused by the alkyl side groups. From the analysis of XRD measurements, more ordered inter-molecular arrangement can be found in the films of PBDTDTBT- $p$ and PBDTDTBT- $o$ than the PBDTDTBT- $m$ film. Interestingly, the $V_{\text {oc }}$ values of the devices based on these three polymers varied from $0.67,0.75$ to $0.90 \mathrm{~V}$, which should be related to the varied HOMO levels of the polymers. Overall, the results in this work show that the fine-tuning of substitution positions of the alkyl side groups plays an important role in modulating photovoltaic properties in 2D-BDT-based polymers.

\section{EXPERIMENTAL SECTION}

\section{Materials and synthesis}

Compound 1, BDT- $p$ and M1 were synthesized through our previous method [41]. $\mathrm{Pd}\left(\mathrm{PPh}_{3}\right)_{4}$ and $\mathrm{Ni}(\mathrm{dppp}) \mathrm{Cl}_{2}$ were purchased from Frontiers Scientific Inc. The monomer DTBT and $\mathrm{PC}_{71} \mathrm{BM}$ were purchased from Solarmer Materials Inc. Tetrahydrofuran (THF) was dried over $\mathrm{Na}$ / benzophenone and freshly distilled prior to use. All of the other commercial available reagents and compounds were 
used as received.

\section{Instruments}

${ }^{1} \mathrm{H}$ NMR spectra were performed on a Bruker arx-400 spectrometer in $\mathrm{CDCl}_{3}$ at room temperature. Absorption spectra were measured on a Hitachi U-3100 UV-vis spectrophotometer. Molecular weights and PDI of the polymers were estimated by gel permeation chromatography (GPC) method using polystyrene as standard and chloroform as eluent. The CHI650D Electrochemical Workstation with Glassy carbon, Platinum wire, and $\mathrm{Ag} / \mathrm{Ag}^{+}$electrode was used to measure the electrochemical potentials of the polymer films, and the measurement was carried out in a 0.1 $\mathrm{M}$ tetrabutylammonium hexafluorophosphate $\left(\mathrm{Bu}_{4} \mathrm{NPF}_{6}\right)$ acetonitrile solution. EQE was measured by a Solar Cell Spectral Response Measurement System QE-R3011 (Enli Technology). The light intensity at each wavelength was calibrated with a standard single-crystal Si photovoltaic cell.

\section{Fabrication of polymer solar cells}

PSC devices were fabricated with a typical structure of ITO/ PEDOT-PSS/polymer: $\mathrm{PC}_{71} \mathrm{BM} / \mathrm{Ca} / \mathrm{Al}$ under the following conditions: after spin-coating a $35 \mathrm{~nm}$ of PEDOT:PSS onto a pre-cleaned ITO glass substrate, the ITO was dried at $150^{\circ} \mathrm{C}$ for $15 \mathrm{~min}$. Then the polymer $/ \mathrm{PC}_{71} \mathrm{BM}\left(10 \mathrm{mg} \mathrm{mL}^{-1}\right.$, based on the polymer weight concentration) blend solutions in $o$-dichlorobenzene was spin-coated. Then, methanol treatment $(\sim 60 \mu \mathrm{L}$ methanol was deposited of active layers at $4000 \mathrm{rpm}$ for $30 \mathrm{~s}$ ) was carried out to improve the reproducibility and efficiency of all of the PSC devices for realizing better interface contacts $[42,43]$. Finally, the devices were accomplished by evaporating $\mathrm{Ca} / \mathrm{Al}$ electrodes with an area of $4.15 \mathrm{~mm}^{2}$. All the fabrication processes except for the spin-coating of the PEDOT:PSS layers were carried out inside a nitrogen glovebox. To obtain reliable results, the current density-voltage $(J-V)$ characteristics were measured under $100 \mathrm{~mW} \mathrm{~cm}^{-2}$ standard AM $1.5 \mathrm{G}$ spectrum by using a Class AAA solar simulator along with a NIM calibrated KG3-filtered reference cells according to our recent report [44].

\section{Synthesis}

\section{2,3-Dioctylthiophene (2)}

To a solution of 2-bromo-3-octylthiophene (30 mmol, 8.28 g) and $\mathrm{Ni}(\mathrm{dppp}) \mathrm{Cl}_{2}(0.36 \mathrm{mmol}, 194 \mathrm{mg})$ in THF $(50 \mathrm{~mL})$, the Grignard reagent $(2 \mathrm{M}, 18 \mathrm{~mL})$ was added dropwise at $0^{\circ} \mathrm{C}$ under the protection of argon. Then the reaction was stirred under reflux overnight. The mixture was quenched by diluted $\mathrm{HCl}$ slowly, washed by water and extracted by ethyl ether twice, then the combined organic layer was concentrated by removing the solvent and the coarse product was purified by distillation, after which the pure compound 2 (4.1 g, yield 44\%) was obtained as colorless liquid. ${ }^{1} \mathrm{H} \mathrm{NMR}\left(\mathrm{CDCl}_{3}, 400 \mathrm{MHz}\right), \delta(\mathrm{ppm}): 6.98(\mathrm{~d}, 1 \mathrm{H}), 6.78(\mathrm{~d}$, $1 \mathrm{H}), 2.73(\mathrm{t}, 2 \mathrm{H}), 2.51(\mathrm{t}, 2 \mathrm{H}), 1.75-1.60(\mathrm{~m}, 4 \mathrm{H}), 1.30(\mathrm{~m}$, $20 \mathrm{H}), 0.88(\mathrm{t}, 6 \mathrm{H})$.

\section{2-Bromo-5-octylthiophene (3)}

In a three neck round flask, $N$-bromosuccinimide (NBS) $(17.8 \mathrm{~g}, 0.1 \mathrm{~mol})$ was added to a solution of 5-octylthiophene (19.6 g, $0.1 \mathrm{~mol}$ ) in $N, N$-dimethylformamide (DMF) $(150 \mathrm{~mL})$ by portions at $0^{\circ} \mathrm{C}$ and the reaction was slowly warmed to room temperature for $2 \mathrm{~h}$. Then the reaction was quenched by $100 \mathrm{~mL}$ of water and extracted by ethyl ether three times. After the solvent of organic phase was removed, the crude product was purified by distillation and compound 3 (24.3 g, yield 88\%) was obtained. ${ }^{1} \mathrm{H}$ NMR $\left(\mathrm{CDCl}_{3}, 400 \mathrm{MHz}\right), \delta(\mathrm{ppm}): 6.84(\mathrm{~d}, 1 \mathrm{H}), 6.53(\mathrm{~d}, 1 \mathrm{H})$, $2.74(\mathrm{t}, 2 \mathrm{H}), 1.65(\mathrm{~m}, 2 \mathrm{H}), 1.31(\mathrm{~m}, 10 \mathrm{H}), 0.89(\mathrm{t}, 3 \mathrm{H})$.

\section{3-Bromo-5-octylthiophene (4)}

To a solution of compound $3(5.52 \mathrm{~g}, 20 \mathrm{mmol})$ in THF $(30 \mathrm{~mL})$, lithium diisopropylamide $(2 \mathrm{M}, 13 \mathrm{~mL})$ was added dropwise at $-78^{\circ} \mathrm{C}$ under protection of argon, then the solution was warmed to room temperature slowly and kept for $16 \mathrm{~h}$. After that the reaction was quenched by water slowly, and the mixture was extracted by ethyl ether twice. The organic phase was concentrated by removing the solvent and the raw product was purified by distillation to get pure compound 4 as a colorless liquid (5.30 g, yield 96\%). ${ }^{1} \mathrm{H} \mathrm{NMR}\left(\mathrm{CDCl}_{3}, 400 \mathrm{MHz}\right), \delta(\mathrm{ppm}): 7.00(\mathrm{~s}, 1 \mathrm{H}), 6.70$ (s, $1 \mathrm{H}), 2.78(\mathrm{t}, 2 \mathrm{H}), 1.66(\mathrm{~m}, 2 \mathrm{H}), 1.31(\mathrm{~m}, 10 \mathrm{H}), 0.90(\mathrm{t}, 3 \mathrm{H})$.

\section{2,4-Dioctylthiophene (5)}

The same method of synthesizing compound 2 was used to prepare compound 5 as a colorless liquid (yield 63\%). ${ }^{1} \mathrm{H} \mathrm{NMR}\left(\mathrm{CDCl}_{3}, 400 \mathrm{MHz}\right), \delta(\mathrm{ppm}): 6.68(\mathrm{~s}, 1 \mathrm{H}), 6.62(\mathrm{~s}$, $1 \mathrm{H}), 2.77(\mathrm{t}, 2 \mathrm{H}), 2.55(\mathrm{t}, 2 \mathrm{H}), 1.70-1.57(\mathrm{~m}, 4 \mathrm{H}), 1.32(\mathrm{~m}$, $20 \mathrm{H}), 0.90(\mathrm{t}, 6 \mathrm{H})$.

4,8-Bis(5-(2-hexyldecyl)thiophen-2-yl)benzo[1,2-b:4,5- $\left.b^{\prime}\right]$ dithiophene (BDT-o)

To a solution of compound $2(6.2 \mathrm{~g}, 20 \mathrm{mmol})$ in THF (20 $\mathrm{mL}), n$-butyllithium $(2.5 \mathrm{M}, 8.8 \mathrm{~mL})$ was added dropwise at $0^{\circ} \mathrm{C}$ under protection of argon, then the mixture was warmed to $50^{\circ} \mathrm{C}$ and stirred for $0.5 \mathrm{~h}$. Subsequently, benzo [1,2-b:4,5-b']dithiophene-4,8-dione (1.1 g, $5 \mathrm{mmol}$ ) was added and stirred for $1 \mathrm{~h}$. A solution of $\mathrm{SnCl}_{2} \cdot 2 \mathrm{H}_{2} \mathrm{O}(9.0$ g, $40 \mathrm{mmol}$ ) in $10 \% \mathrm{HCL}$ was added when the reactant came back to room temperature, then the reactant was stirred for another $2 \mathrm{~h}$. The mixture was poured into ice water and extracted with diethyl ether three times, and the 
organic phase was concentrated by removing the solvent. The coarse product was purified by silica gel chromatography using petroleum ether as eluent to get pure BDT-o (1.40 g, yield 35\%). ${ }^{1} \mathrm{H} \mathrm{NMR}\left(\mathrm{CDCl}_{3}, 400 \mathrm{MHz}\right), \delta(\mathrm{ppm})$ : $7.69(\mathrm{~d}, 2 \mathrm{H}), 7.45(\mathrm{~d}, 2 \mathrm{H}), 7.21(\mathrm{~s}, 2 \mathrm{H}), 2.84(\mathrm{t}, 4 \mathrm{H}), 2.62$ (t, 4H), 1.76-1.61 (m, 8H), 1.45-1.30 (m, 40H), 0.90-0.84 (m, 12H).

\section{4,8-Bis(2,4-dioctylthiophene-5-yl)benzo[1,2-b;4,5- $\left.b^{\prime}\right]$ dith- iophene (BDT-m)}

Under the protection of argon, $n$-butyllithium (2.5 M, 8.8 $\mathrm{mL})$ was added dropwise into a solution of compound 5 $(6.20 \mathrm{~g}, 20 \mathrm{mmol})$ in $\mathrm{THF}(20 \mathrm{~mL})$ at $0^{\circ} \mathrm{C}$, then the mixture was warmed up to $50^{\circ} \mathrm{C}$ and stirred for $0.5 \mathrm{~h}$. Subsequently, 4,8-dehydrobenzo[1,2-b:4,5-b'] dithiophene-4,8-dione (1.1 $\mathrm{g}, 5 \mathrm{mmol}$ ) was added and the mixture was stirred for $1 \mathrm{~h}$ at $50^{\circ} \mathrm{C}$. After cooling down to ambient temperature, a mixture of $\mathrm{SnCl}_{2} \cdot 2 \mathrm{H}_{2} \mathrm{O}(9.0 \mathrm{~g}, 40 \mathrm{mmol})$ in $10 \% \mathrm{HCl}$ was added and the mixture was stirred for additional $2 \mathrm{~h}$. Then the mixture was poured into ice water, extracted by ethyl ether twice and the combined organic phase was concentrated to obtain raw compound BDT- $m$. Further purification was carried out by a chromatographic column using petroleum ether as eluent to obtain pure compound BDT- $m$ as yellow stick liquid (1.84 g, yield $46 \%) .{ }^{1} \mathrm{H} \mathrm{NMR}\left(\mathrm{CDCl}_{3}\right.$, $400 \mathrm{MHz}), \delta$ (ppm): 7.39 (d, 2H), $7.24(\mathrm{~m}, 2 \mathrm{H}), 6.78(\mathrm{~s}$, $2 \mathrm{H}), 2.88(\mathrm{t}, 4 \mathrm{H}), 2.36(\mathrm{t}, 4 \mathrm{H}), 1.77(\mathrm{~m}, 8 \mathrm{H}), 1.36(\mathrm{br}, 40 \mathrm{H})$, $0.91-0.79(\mathrm{~m}, 12 \mathrm{H})$.

2,6-Bis(trimethyltin)-4,8-bis(2,3-dioctylthiophene-5-yl)ben$z o\left[1,2-b ; 4,5-b^{\prime}\right]$ dithiophene (M2)

Under the protection of argon, $n$-butyllithium (2.5 M, 2.0 $\mathrm{mL})$ was added dropwise into the solution of BDT- $o$ (1.60 g, $2.0 \mathrm{mmol})$ in THF $(30 \mathrm{~mL})$ at room temperature and stirred for $2 \mathrm{~h}$ at $50^{\circ} \mathrm{C}$. Then trimethyltin chloride $(1.0 \mathrm{M}$, $6 \mathrm{~mL}$ ) was added to the solution at room temperature. 2 $\mathrm{h}$ later, the reaction was quenched by water $(80 \mathrm{~mL})$ and extracted by ethyl ether twice. After removing the solvent, the crude compound M2 was purified by recrystallized to obtain pure compound M2 as light yellow powder (1.42 g, yield $63 \%) .{ }^{1} \mathrm{H}$ NMR $\left(\mathrm{CDCl}_{3}, 400 \mathrm{MHz}\right), \delta(\mathrm{ppm}): 7.73(\mathrm{~s}$, $2 \mathrm{H}), 7.24(\mathrm{~s}, 2 \mathrm{H}), 2.86(\mathrm{t}, 4 \mathrm{H}), 2.64(\mathrm{t}, 4 \mathrm{H}), 1.78-1.63(\mathrm{~m}$, $8 \mathrm{H}), 1.46-1.30$ (br, $40 \mathrm{H}), 0.90(\mathrm{~m}, 12 \mathrm{H}), 0.40(\mathrm{~m}, 18 \mathrm{H})$.

2,6-Bis(trimethyltin)-4,8-bis(2,4-dioctylthiophene-5-yl)ben$z o\left[1,2-b ; 4,5-b^{\prime}\right]$ dithiophene (M3)

$n$-Butyllithium (2.5 M, $2.08 \mathrm{~mL})$ was added dropwise into the solution of BDT- $m(1.60 \mathrm{~g}, 2.0 \mathrm{mmol})$ in THF $(30 \mathrm{~mL})$ at room temperature under the protection of argon, and the mixture stirred for $2 \mathrm{~h}$ at $50^{\circ} \mathrm{C}$. Then trimethyltin chloride $(1.0 \mathrm{M}, 6 \mathrm{~mL})$ was added to the solution at room temperature and stirred for $2 \mathrm{~h}$. Then the reaction was quenched by water $(80 \mathrm{~mL})$ and extracted by ethyl ether twice. After removing the solvent, the crude compound M3 was purified by recrystallized to obtain pure compound M3 (1.78 g, yield $79 \%) .{ }^{1} \mathrm{H} \mathrm{NMR}\left(\mathrm{CDCl}_{3}, 400 \mathrm{MHz}\right), \delta$ (ppm): 7.72(s, $2 \mathrm{H}), 7.30$ (s, 2H), 2.88 (t, 4H), 2.36 (t, 4H), $1.74(\mathrm{~m}, 8 \mathrm{H})$, 1.41-1.31 (br, 40H), 0.91-0.79 (m, 12H), 0.40 (s, 18H).

Polymerization of PBDTDTBT-p, PBDTDTBT-o, PBDTDTBT-m

BDT monomer $(0.5 \mathrm{mmol})$ and DTBT monomer $(0.5$ mmol) were put into a $50 \mathrm{~mL}$ two-neck flask, and $10 \mathrm{~mL}$ of toluene was added. The mixture was stirred and purged with argon for 5 minutes, and then $20 \mathrm{mg}$ of catalyst $\mathrm{Pd}\left(\mathrm{PPh}_{3}\right)_{4}$ was added. After being purged for 20 minutes, the mixture was put into a $110^{\circ} \mathrm{C}$ oil bath. After $14 \mathrm{~h}$, the reaction was quenched by adding $20 \mathrm{~mL}$ of methanol. The solid was filtered into a Soxhlet funnel and extracted by methanol, hexane, and chloroform successively. The chloroform fraction was collected, concentrated and precipitated from a large amount of methanol. The precipitants were filtered and dried under vacuum. The yield and elemental analytical data of the polymers are as follows.

PBDTDTBT- $p$ : Yield $61 \%$. Calculated for $\mathrm{C}_{64} \mathrm{H}_{78} \mathrm{~N}_{2} \mathrm{~S}_{7}$ : C, 69.89; H, 7.15; N, 2.55; S, 20.41; Found: C, 69.77; H, 7.14; $\mathrm{N}, 2.49 . M_{\mathrm{n}}=28 \mathrm{kDa}$ PDI $=1.9$.

PBDTDTBT-o: Yield 58\%. Calculated for $\mathrm{C}_{64} \mathrm{H}_{78} \mathrm{~N}_{2} \mathrm{~S}_{7}$ : C, 69.89; H, 7.15; N, 2.55; S, 20.41; Found: C, 69.87; H, 7.11; $\mathrm{N}, 2.52 . M_{\mathrm{n}}=25 \mathrm{kDa}$ PDI $=1.7$.

PBDTDTBT- $m$ : Yield 37\%. Calculated for $\mathrm{C}_{64} \mathrm{H}_{78} \mathrm{~N}_{2} \mathrm{~S}_{7}$ : C, 69.89; H, 7.15; N, 2.55; S, 20.41; Found: C, 69.85; H, 7.14; $\mathrm{N}, 2.55 . M_{\mathrm{n}}=18 \mathrm{kDa}$ PDI $=1.8$.

\section{Received 24 January 2015; accepted 13 February 2015; published online 16 March 2015}

1 Dou L, You J, Hong Z, et al. 25th anniversary article: a decade of organic/polymeric photovoltaic research. Adv Mater, 2013, 25: 6642-6671

2 Cheng YJ, Yang SH, Hsu CS. Synthesis of conjugated polymers for organic solar cell applications. Chem Rev, 2009, 109: 5868-5923

3 Chen J, Cao Y. Development of novel conjugated donor polymers for high-efficiency bulk-heterojunction photovoltaic devices. Acc Chem Res, 2009, 42: 1709-1718

4 Beaujuge PM, Fréchet JMJ. Molecular design and ordering effects in $\pi$-functional materials for transistor and solar cell applications. J Am Chem Soc, 2011, 133: 20009-20029

5 Li YF. Molecular design of photovoltaic materials for polymer solar cells: toward suitable electronic energy levels and broad absorption. Acc Chem Res, 2012, 45: 723-733

6 Zhou HX, Yang LQ, You W. Rational design of high performance conjugated polymers for organic solar cells. Macromolecules, 2012, 45: 607-632

7 Duan C, Huang F, Cao Y. Recent development of push-pull conjugated polymers for bulk-heterojunction photovoltaics: rational design and fine tailoring of molecular structures. J Mater Chem, 2012, 22: 10416-10434

8 Ye L, Zhang S, Huo L, Zhang M, Hou J. Molecular design toward 
highly efficient photovoltaic polymers based on two-dimensional conjugated benzodithiophene. Acc Chem Res, 2014, 47: 1595-1603

9 Huo LJ, Hou JH. Benzo[1,2-b:4,5-b']dithiophene-based conjugated polymers: band gap and energy level control and their application in polymer solar cells. Polym Chem, 2011, 2: 2453-2461

10 You J, Dou L, Yoshimura K, et al. A polymer tandem solar cell with 10.6\% power conversion efficiency. Nat Commun, 2013, 4: 1446

11 Tan Z, Li S, Wang F, et al. High performance polymer solar cells with as-prepared zirconium acetylacetonate film as cathode buffer layer. Sci Rep, 2014, 4: 4691

12 Ye L, Zhang SQ, Ma W, et al. From binary to ternary solvent: morphology fine-tuning of D/A blends in PDPP3T-based polymer solar cells. Adv Mater, 2012, 24: 6335-6341

13 Li W, Furlan A, Hendriks KH, Wienk MM, Janssen RAJ. Efficient tandem and triple-junction polymer solar cells. J Am Chem Soc, 2013, 135: 5529-5532

14 Li K, Li Z, Feng K, et al. Development of large band-gap conjugated copolymers for efficient regular single and tandem organic solar cells. J Am Chem Soc, 2013, 135: 13549-13557

15 He ZC, Zhong CM, Su SJ, et al. Enhanced power-conversion efficiency in polymer solar cells using an inverted device structure. Nat Photonics, 2012, 6: 591-595

16 Chen CC, Chang WH, Yoshimura K, et al. An efficient triple-junction polymer solar cell having a power conversion efficiency exceeding 11\%. Adv Mater, 2014, 26: 5670-5677

17 Li XH, Choy WCH, Huo LJ, et al. Dual plasmonic nanostructures for high performance inverted organic solar cells. Adv Mater, 2012, 24: 3046-3052

18 Yang TB, Wang $\mathrm{M}$, Duan $\mathrm{CH}$, et al. Inverted polymer solar cells with $8.4 \%$ efficiency by conjugated polyelectrolyte. Energ Environ Sci, 2012, 5: 8208-8214

19 Liu S, Zhang K, Lu J, et al. High-efficiency polymer solar cells via the incorporation of an amino-functionalized conjugated metallopolymer as a cathode interlayer. J Am Chem Soc, 2013, 135: 1532615329

20 Liao SH, Jhuo HJ, Cheng YS, Chen SA. Fullerene derivative-doped zinc oxide nanofilm as the cathode of inverted polymer solar cells with low-bandgap polymer (PTB7-Th) for high performance. Adv Mater, 2013, 25: 4766-4771

21 Li CZ, Chang CY, Zang Y, et al. Suppressed charge recombination in inverted organic photovoltaics via enhanced charge extraction by using a conductive fullerene electron transport layer. Adv Mater, 2014, 26: 6262-6267

22 Zhang S, Ye L, Zhao W, et al. Side chain selection for designing highly efficient photovoltaic polymers with $2 \mathrm{D}$-conjugated structure. Macromolecules, 2014, 47: 4653-4659

23 Zhou H, Zhang Y, Mai CK, et al. Conductive conjugated polyelectrolyte as hole-transporting layer for organic bulk heterojunction solar cells. Adv Mater, 2014, 26: 780-785

24 Liu P, Zhang K, Liu F, et al. Effect of fluorine content in thienothiophene-benzodithiophene copolymers on the morphology and performance of polymer solar cells. Chem Mater, 2014, 26: 3009-3017

25 Ye L, Zhang S, Zhao W, Yao H, Hou J. Highly efficient 2D-conjugated benzodithiophene-based photovoltaic polymer with linear alkylthio side chain. Chem Mater, 2014, 26: 3603-3605

26 Cui C, Wong WY, Li Y. Improvement of open-circuit voltage and photovoltaic properties of $2 \mathrm{D}$-conjugated polymers by alkylthio substitution. Energ Environ Sci, 2014, 7: 2276-2284

27 Tan ZA, Li LJ, Wang FZ, et al. Solution-processed rhenium oxide: a versatile anode buffer layer for high performance polymer solar cells with enhanced light harvest. Adv Energy Mater, 2014, 4: 1300884

28 Zhao W, Ye L, Zhang S, et al. Ultrathin polyaniline-based buffer lay- er for highly efficient polymer solar cells with wide applicability. Sci Rep, 2014, 4: 6570

29 Zhang M, Gu Y, Guo X, et al. Efficient polymer solar cells based on benzothiadiazole and alkylphenyl substituted benzodithiophene with a power conversion efficiency over 8\%. Adv Mater, 2013, 25: 4944-4949

30 Wang N, Chen Z, Wei W, Jiang Z. Fluorinated benzothiadiazole-based conjugated polymers for high-performance polymer solar cells without any processing additives or post-treatments. J Am Chem Soc, 2013, 135: 17060-17068

31 Cabanetos C, El Labban A, Bartelt JA, et al. Linear side chains in benzo[1,2-b:4,5-b']dithiophene-thieno[3,4-c]pyrrole-4,6-dione polymers direct self-assembly and solar cell performance. J Am Chem Soc, 2013, 135: 4656-4659

32 Lei T, Wang JY, Pei J. Roles of flexible chains in organic semiconducting materials. Chem Mater, 2013, 26: 594-603

33 Mei J, Bao Z. Side chain engineering in solution-processable conjugated polymers. Chem Mater, 2013, 26: 604-615

34 Zhang ZG, Li YF. Side-chain engineering of high-efficiency conjugated polymer photovoltaic materials. Sci China Chem, 2015, 58: 192-209

35 Huang Y, Zhang M, Ye L, et al. Molecular energy level modulation by changing the position of electron-donating side groups. J Mater Chem, 2012, 22: 5700-5705

36 Huang F, Chen KS, Yip HL, et al. Development of new conjugated polymers with donor- $\pi$-bridge-acceptor side chains for high performance solar cells. J Am Chem Soc, 2009, 131: 13886-13887

37 Dong Y, Hu X, Duan C, et al. A series of new medium-bandgap conjugated polymers based on naphtho[1,2-c:5,6-c]bis(2-octyl-[1,2,3] triazole) for high-performance polymer solar cells. Adv Mater, 2013, 25: 3683-3688

38 Huo LJ, Hou JH, Zhang SQ, Chen HY, Yang Y. A polybenzo[1,2-b:4 $5-b^{\prime}$ '] dithiophene derivative with deep HOMO level and its application in high-performance polymer solar cells. Angew Chem Int Ed, 2010, 49: 1500-1503

39 Peng Q, Liu X, Su D, et al. Novel benzo[1,2-b:4,5-b'] dithiophenbenzothiadiazole derivatives with variable side chains for high-performance solar cells. Adv Mater, 2011, 23: 4554-4558

40 Frisch MJ, Trucks GW, Schlegel HB, et al. Gaussian 09. Wallingford: Gaussian, Inc., 2009

41 Huo L, Guo X, Zhang S, Li Y, Hou J. PBDTTTZ: a broad band gap conjugated polymer with high photovoltaic performance in polymer solar cells. Macromolecules, 2011, 44: 4035-4037

42 Ye L, Jing Y, Guo X, et al. Remove the residual additives toward enhanced efficiency with higher reproducibility in polymer solar cells. J Phys Chem C, 2013, 117: 14920-14928

43 Wang Y, Liu Y, Chen S, Peng R, Ge Z. Significant enhancement of polymer solar cell performance via side-chain engineering and simple solvent treatment. Chem Mater, 2013, 25: 3196-3204

44 Ye L, Zhou C, Meng $\mathrm{H}$, et al. Toward reliable and accurate evaluation of polymer solar cells based on low band gap polymers. J Mater Chem C, 2015, 3: 564-569

Acknowledgements This work was supported by the National Basic Research Program (2014CB643500), the National Natural Science Foundation of China (91333204 and 51261160496), and the Chinese Academy of Sciences (XDB12030200 and KJZDEW-J01).

Author contributions Hou J and Huo L designed this work. Yao H synthesized the materials and wrote the paper. Ye L and Fan B conducted the other experiments. All authors contributed to discuss the results.

Conflict of interest The authors declare that they have no conflict of interest. 

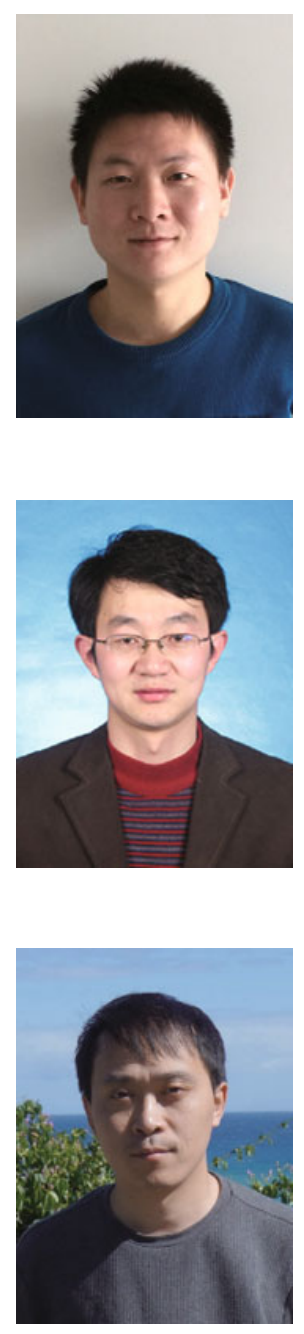

Huifeng Yao is a PhD candidate at the Institute of Chemistry, Chinese Academy of Sciences (ICCAS) under the supervision of Prof. Jianhui Hou. His research interests focus on the design and synthesis of high performance organic photovoltaic materials.
Lijun Huo received his PhD degree from China University of Mining and Technology in 2010. He was an associate professor in Prof. Jianhui Hou's group at ICCAS, and then joined Beihang University in 2014. His current research interests are the design and synthesis of organic photovoltaic materials.
Jianhui Hou received his PhD degree from ICCAS in 2006. Then he worked as a postdoctoral researcher in Prof. Yang Yang's group at the University of California at Los Angeles. He joined the Solarmer Energy Inc. (USA) in 2008 as a team leader of research department. He became a full professor at ICCAS since 2010, and his research focuses on the design, synthesis and application of the organic/polymer photovoltaic materials. In the past few years, he has co-authored more than 100 papers in peer-reviewed journals and 18 patents.

中文摘要 本文将具有不同取代位点的二维共轭支链引入到 PBDTDTBT 类聚合物的苯并二噻吩单元上, 设计和合成了三种骨架相同 的二维共轭聚合物, 即 PBDTDTBT- $p$, PBDTDTBT- $o$ 和 PBDTDTBT- $m$, 并在此基础上探究了烷基链取代位点对共轭聚合物的光伏性质 以及器件性能的影响. 通过吸收光谱、循环伏安、热失重分析、 $\mathrm{X}$ 射线衍射、光伏测试以及理论计算等手段对比研究了三种聚合物光 伏材料, 结果表明由不同烷基链取代位点引起的分子空间位阻作用对三种聚合物的光物理性质、微观形貌以及光伏性能有着重要的影 响. 基于三种聚合物制备的光伏器件的开路电压可从 $0.67 \mathrm{~V}$ 变化到 $0.90 \mathrm{~V}$, 其光伏效率也相应地从 $3.48 \%$ 提高到 $5 \%$ 以上. 调节烷基链 取代位点是一种简单有效制备高性能聚合物光伏材料的优化策略. 